\title{
LA LITERATURA MEXICANA Y LA EXPERIENCIA COMUNITARIA
}

\author{
PRESENTACION
}

POR

JULIO ORTEGA

Brown University

Si en un país tiene sentido la tradición literaria es en México: una literatura nacional se constituye como su versión distintiva. Y si la tradición literaria nos provec de una experiencia imaginaria común, la litcratura nacional nos hace lectores peculiares, cs decir, individuos cspecíficos. La litcratura mexicana es, en más de un sentido, nuestra: la experiencia histórica moderna (colonialismo, imperialismo, neo-conscrvadurismo) es respondida desde su reformulación latinoamericana (la nacionalidad, la revolución, la socialización). Lo mexicano de cstas respuestas no se circunscribe al Estado autoritario y benefactor (ese "ogro filantrópico" cuyo ojo ciclópico es el PRI); aun cuando cl papel socializador del Estado sca a veces decisivo para mediar los efectos de la modernización sin democratización que caracteriza a nuestros paises; y no es casual que las actuales fuerzas nco-conservadoras busquen climinar esa función. Más bien, lo mexicano đe csas respuestas está en la capacidad social y política para producir una versión nacional del vivir y sobrevivir lo moderno. O sea, la capacidad para producir espacios humanizados por la intcracción social. No en vano México tuvo su revolución temprano. Y a pesar de todas las limitaciones evidentes, la vida cotidiana está más democratizada por el lenguaje común de la historicidad social, esa práctica del consenso. En otros países nuestros (pienso en el mío, en el Perú, como cl cjemplo más flagrante) ese desafío ni siquicra se ha planteado: si la vida cotidiana es naturalmente antidemocrática quiere decir que la modernidad carece de contenido social.

La literatura - ese diálogo horizontal con cl otro- es una fuerza democratizadora, tanto por su apelación al tú del lector, semejante en el lenguaje con que rehacemos este mundo diferente; como por su apelación crítica, impugnadora y desfundante, capaz de poner en duda los privilegios de la idcología que pasa por única verdad posible. Si la historia es la actualidad, el mito es el pasado: lo histórico encarna en mitos, y la subjetividad colectiva es figurada por la letra y la 
lectura. En Pedro Páramo, por ejemplo, nos encontramos con una peculiaridad mexicana de la tradición: el mito del retorno (que promete la identidad de la abundancia paradisíaca) es recscrito desde la historia del hijo negado por el poder patriarcal que borra hasta la letra de su identidad. Así, este relato responde a dos de las construcciones ideológicas más poderosas de la colonización española: $\mathrm{cl}$ poder se basa en la propicdad de la tierra, y en esa propiedad se sustenta la legitimidad del hijo. Ese horizonte del mundo pre-moderno es revocado gracias a una de las armas mås sofisticadas de la modernidad: la novela. En la dimensión política de la cultura (donde trabajan nuestros mejores textos) esta novela nos dice no la simpleza de que la revolución ha fracasado sino el hecho de que el caciquismo y cl autoritarismo son formas tradicionales corruptoras y negadoras de la revolución y de lo moderno, y que deben ser desfundados como construcción ideológica por la nueva cultura, aquella que se adelanta en la novela misma. En la obra de Carlos Fuentes la identidad de los hijos (csos nuevos lectores hechos por la modernización narrativa) puede liberamos de la tiranía de los mitos que distorsionan, incautan o nicgan la experiencia democratizadora de lo moderno. Sus novelas cstán animadas por la pasión desmitificadora a nombre de la otra construcción, la más difícil: la de una colectividad democrática (pluralista), moderna (critica y socializadora), y nuestra (diferente en un mundo que hemos ayudado a hacerse plural). Si en la obra de Octavio Paz la experiencia de un latinoamericano adquiría la dignidad de su libertad de opciones, en la de Carlos Fuentes esa experiencia se cree capaz de rehacer el mundo moderno con sus propias demandas y versiones. Que éste es un proceso que parie de la existencia cotidiana y comunitaria, y que por lo mismo está hecho no de grandes palabras sino de la palabra zozobrante de la sobrevivencia diaria, se hace patente en la obra de José Emilio Pacheco; esa obra, una de las măs ficles y solidarias, revela desde la conciencia agonista de la crítica cl drama de una modernidad que genera nuevos desheredados.

Desde Fernández de Lizardi hasta Carlos Monsiváis, desde López Velarde hasta David Hucrta, la experiencia mexicana de lo comunitario ha sido una de las formas críticas más desgarradas y solidarias de la modernidad. Si la noción de patria es para Lizardi, como para Fray Servando Teresa de Mier, el teatro de intereses en disputa, ante el cual la lucidez racionalista cede al escepticismo o la indignación; para López Velarde, como para Jaime Sabines, será un delicado refugio en la intimidad no de la provincia sino de la lengua, en una desnudez del decir adelgazado o cxasperado, que oponen a la historia la afirmación apelativa del diálogo, aunque sea un diálogo fantasmático. En cambio, para Monsiváis lo colectivo cs un cspectáculo de máscaras y papeles donde la represión, el ncocolo- 
nialismo y la mitología del consumo deshumanizan al sujeto social a travćs de la destrucción de su espacio comunitario; en la tradición argumentativa de Lizardi, con la lucidez exasperada de Efraín Huerta y José Revucltas, Monsiváis ha levantado una versión política de la vida cotidiana, paralela a la de Carlos Fuentes. El cspacio ritual de la fiesta, consagrado por Octavio $\mathrm{Pa} z$ como cl instante revclador de lo vivo, ha sido ocupado por la mitologización del poder y la alienación del sujeto. Sólo que en ese mismo espectáculo lo colectivo se reconstruye con sus respuestas, su dignidad, sus apuestas. Si Lizardi, como ha demostrado muy bien Jcan Franco, promovió el papel de la escritura como una de las bases del nuevo Estado liberal, Carlos Monsiváis más bien confirma que cl ciclo se ha cerrado: la escritura es una de las bases de la sociedad civil, no por depredada menos viva. $Y$, como ha dicho Norma Klahn, es revelador que el discurso cultural de Monsiváis sea para los más jóvenes el paradigma critico de los años 80. Por su parte, José Emilio Pacheco ha dado al lenguaje una demanda más ardua: la de sosiener - en la calástrofe- el sentido social del consenso. Después de los privilegios del yo como eje revelador (esa crótica del asombro, magníficamente explorada por Octavio Paz), Pacheco se aventura a una épica del tú civil y urbano, cxplorando cl cje de la comunicación como el espacio de inteligencia colectiva donde la dignidad de estar vivos nos obliga al otro, nos debe al nosotros. Si Rulfo y Paz son las grandes instancias de la validación de un lenguaje propio frente a la tradición; Fuentes, Monsiváis y Pacheco amplían esa fundación crítica con la discursividad narrativa, con cl dialogismo de la crónica y con la pocsía afincada cn cl cambio de lo diario; con lo cual un tiempo específico es restituido como experiencia histórica para la reconstrucción del nosotros, de su pragmática transformadora. Si no se ha dicho aún, es hora de decirlo: Monsiváis y Pacheco son los herederos directos del mejor pensamiento crítico de Octavio $\mathrm{Paz}$, cl pensamiento intransigente y gencroso; tanto como Fucntes ha novelizado, hasta sus extremos de disolución paródica, esa reflexión, dándole la actualidad de la fábula. No son tampoco cllos ajenos al magnífico cjemplo de Fernando Benítcz, cuya capacidad de indignación es una lección de moral civil.

La patria (áspera o suave) es el lenguaje haciéndose, en cl que somos hechos. $Y$ cs lo comunitario, su actualidad y su virtualidad, lo que la litcratura convoca a través de la imaginación de lo nuevo, que nos anticipa en un espacio hecho en la comunicación identificatoria. Al margen de los espacios controlados por los aparatos (efectivos c idcológicos) del Estado, el movimiento de reconstrucción de la sociedad civil desde abajo, desde nuevas agrupaciones y concurrencias, es hoy mismo un poderoso proceso de socialización de los espacios y de los discursos; y a ese movimiento corresponden las nuevas aperturas y las claboraciones descentradoras del texto litcrario actual. 
Por otra parte, en la literatura mexicana uno recobra una peculiar entonación de la lectura. Lecr iextos mexicanos es reconocer la textura de una tradición hecha de tramas y relieves de forma trabajada y materia fusionada: como un modelo de la misma litcratura hispanoamericana, la mexicana asume, procesa y transforma los materiales, recursos y mecanismos de la tradición occidental y lo hace con una formalidad expansiva y brillante (desde Sor Juana Inés de la Cruz), no sólo con la discreción del decir reticente que Alfonso Reyes escuchó como un acento nacional mexicano en el teatro laborioso de Alarcón. Más bien, esta expansión formal, csta ligera desmesura, no ha sido reconocida como distintiva, y su importancia ha sido pospucsta, me parece, ante el discreto clasicismo del decir. Pero el propio Alfonso Reyes, de brevedades clocuentes, y de una intimidad del decir regustado, se entregó a excesos discursivos típicos más de la glosa que de la filología. $Y$ en su espléndida versión paródica de Barba Azul produjo un desmesurado tour de force de humor, erotismo y pocsía. El mismo Pedro Páramo, que hace de su laconismo otra forma de su discurso de la carencia (el discurso que denuncia la reducción de lo humano, que es polar al otro discurso nuestro, cl de la abundancia, que promete el sentido), es una novela exccsiva de un modo extraordinario: sus personajes están mucrtos y el mundo es inexistente. ¿Cómo no reconocer la exaltación, incluso la vehemencia, de los mejores poemas de Octavio Paz? Vértigo y fijeza se funden, con trazo de claridad dura y durable, en el contrapunto barroco de esos pocmas. Incluso en las cstampas amables de Juan Josć Arrcola hay cl gesto de un arrebato, la nostalgia de un discurso mayor que lo dijera todo. De ese ardor nostálgico por decirlo todo estuvo hecha la poesía de Carlos Pellicer, cuya estrofa csculpida y versos plenos tienen una fácil complejidad. $Y$ no se han hecho sino más actuales la íntima violencia de la comunión poética en Efraín Hucria, cl desgarrado confesionalismo de Sabines, cl hiperbolismo imaginista de Montes de Oca, la expansividad de la empatía en Tomás Segovia, el hermetismo irónico de Gerardo Deniz, cl sarcasmo agonista de Eduardo Lizalde. En un poema de más de 200 páginas David Huerta ha radicalizado esta latente o explícita necesidad de ir más allá de las mesuras y discreciones, y entregarse a la hipérbole circular de la pocsía del habla, a ese flujo y fluir sin comienzo y sin fin. No menos radical es la propuesta de Alberto Blanco, aunque sca más formal: su universo interior se amplía en las metáforas del arte pictórico hecho verbo. En la narrativa, Carlos Fuentes, otra vez, señala con brillo cl camino del riesgo, sin temor a los acabados y los resultados, apasionado por los procesos y por la inmediatez protcica de la fábula. Su práctica post-moderna supone la noción (novelesca por definición y poética por formal) de que la literatura está hecha en cl cambio, y por lo mismo cada texto es irrepetible. Incluso poctas de decir económico, como Gabricl Zaid o Pacheco, demuestran una fe en la palabra 
que hace de su registro más suscinto una reitcrada afirmación del interlocutor que convocan.

Evidentemente, una gran literatura no está hecha de mesuras. Allí está José Revucitas, cxcesivo por excelencia, para demostrarlo. En la literatura mexicana, este drama de una forma de la inteligencia comunicativa y una pasión expresiva $\mathrm{e}$ inclusiva se da como peculiar, excediendo los modelos dados, rebasando los cánones autorizados. $Y$, sobre todo, dando lugar a un coloquio reverberante, de una vida instantånea, populosa y ardicnte. Si la narrativa cubana es de una materialidad más celebratoria, si la poesia peruana se expande en un arabesco más audaz, si la pocsía chilena desata los códigos de la representación naturail, si la literatura argentina pucde scr más imaginativa y lúdica, la literatura mexicana, en cambio, cspera ser dicha, actuada, encarnada. Se concibe como un instrumento de este mundo, para celebrar sus asombros y remover sus escombros, para hacer y rehacer Ios espacios de lo comunitario, su extravío y su promesa. Hasta en cl espectáculo de la catástrofe brilla ese lenguaje con su tienna crudeza (Hucrta, Sabines, Rosario Castellanos, Eraclio Zepeda, los jóvenes coloquialistas), con su festividad sensórea (Paz, Alí Chumaccro, Segovia, Montes de Oca, Aridjis, Blanco, David Hucrta), con su lucidez urgente, apelativa (Lizalde, Zaid, Pacheco). Y ya hay una nucva promoción de poctas, que đemandan nucstra atención por la scricdad de sus proyectos, y la inmediata autenticidad de su trabajo: Coral Bracho, Fabio Morábito, Jaime Reyes, Ricardo Yañez, Migucl Angel Flores, Rafacl Vargas, Isabel Quiñónez, Manuel Ulacia, Ricardo Castillo, Carmen Boullosa, Verónica Volkow, Francisco Segovia y José Luis Rivas son algunos de ellos.

¿Cómo no mencionar, por otro lado, la importancia en la literatura mexicana actual de las escritoras? Su acento es inconfundible, pero no sólo por tratarse de mujeres que escriben sino por la calidad con que lo hacen desde la condición femenina, ese otro paradigma del tú construido por una modernidad emancipadora. Escritoras como Elena Poniatowska, Julicta Campos, Margo Glantz y María Luisa Puga, son bien conocidas por su valor intelectual y su pasión crítica, como también por la calidad indagatoria que comunican a sus exploraciones de la identidad femenina. Silvia Molina y Carmen Boullosa escriben también una prosa convocatoria, animada por su necesidad de csclarecimicnto, y su humor paradójico. Y Cristina Pacheco, desde la crónica y cl testimonio, hace de los géneros un operativo de concurrencia, abriendo el discurso a los marginados. Apenas hemos empezado a lecr a estas escritoras con la atención que demanda su propia versión de la experiencia comunitaria.

En estos años ha ocurrido, además, cl cxtraordinario resurgimiento del cuento, un género privilegiado en México desde el modernismo decimonónico como una 
de las imágenes de la modernidad y sus estilos de vida, novedad, y urbanidad. Ha sido tambićn metáfora de lo contrario: de las frustraciones impuestas por la modernización, por la violencia y su secuela. Y en Rulfo y Arreola tuvo dos de sus modelos más influyentes. Pucs bien, hoy el nucvo cuento conoce un desarrollo cspléndido. Baste citar a David Ojeda, Juan Villoro, Luis Zapata, Francisco Hernández, Danicl Sada, Oscar de la Borbolla, Agustín Ramos, Luis Arturo Ramos, además de las ya mencionadas Molina y Boullosa. Luego de los más reconocidos narradores de la Onda, que favorecicron un relato oralizado, narradorcs como Jorge Aguilar Mora y Héctor Manjarrez iniciaron un proceso diferente, a partir de la exploración de la escritura como forma de la experiencia misma de una generación que, despućs de Tlatelolco, sólo podía recomenzar desde su propia capacidad de devolver un sentido al horizonte comunitario, recusado por ci autoritarismo y la violencia. El nuevo cuento mexicano no ignora los dramas del espacio social en que sc inscribe, pero aporta a su desciframicnto una reafirmación individual, un culto por la aventura y el juego; y una visión claborada y compleja de la disgregación y la crisis generalizada. En el centro del malestar social, esios jóvenes reafirman el poder impugnador de la palabra; y lo hacen con laconismo, con un subrayado grotcsco, desdramatizando al sujcto con humor absurdista. Esa habla mexicana dice la vida de hoy, pero dice también que el sujeto colectivo que la encarna no ha cesado de negar y de afirmar.

Distintas formas de autodestrucción y de mucrte son representadas en esa nueva narrativa con distanciada irreverencia festiva, aunque esa metáfora de la crisis no es ya mexicana sino latinoamericana. Y es sólo justo que los más jóvenes busquen dar a la crisis, que se ha vuelto ya su medio natural, una representación a su vez fracturada y desasida. La mucrte ha dejado de ser un tópico mexicano, y se ha convertido en un referente diario de nuestros países con índices de vida cada vez más reducidos por el costo popular de las deudas que nos definen. Pero relcyendo poesía mexicana me encontré con que este tema de la mucrte es el menos clásico o mesurado de csa pocsía. De modo que en cada uno de los ejemplos que siguen podría verse una poćtica extremada, y no sólo por la expresividad sino por la necesidad de contradicción, de respucsta. Lo vemos en Efraín Hucrta cuando habla de la muerte de Rubén Darío y espanta a los cisnes de este y del otro mundo:

Claro está que murió -como deben morir los poetas, maldiciendo, blasfemando, mentando madres, riendo apariciones, cobijado por las pesadillas.

En cambio, Octavio Paz quicre aferrar a la mucrte para conocerla y, paradoja poćtica extrema, cncarnarla: 
La muerte que yo quiero lleva mi nombre, tiene mi cara.

Jaime Sabines, por su parte, se escandaliza ante el ceremonial de pocta nacional con que enterraron a Rosario Castellanos:

(¿No me vayan a hacer a mí esa cosa

de los Hombres Ilustres, con una chingada!)

Eduardo Lizalde cnuncia un dilema clásico con verso de simetría barroca:

Del tiempo he de morir, magro es mi tiempo.

José Emilio Pacheco se dirige al pocta nacional convertido en poder incólume y adclanta su cpitafio moral:

Mañana serás polvo y error.

Si en cse verso la hipćrbole barroca (polvo, nada) y la consolación paradójica (polvo cnamorado) son reformuladas por la precaricdad mundana de las repúblicas literarias, en las cuales el escritor mås consagrado cs cl más frágil; cn estos de Gabricl Zaid la mucrie moral aguarda en cl sistema a los rebeldes que ayer lo combaticron y hoy lo perpelúan:

Intenté suicidarme gritando jmuera el PRI!

Yrecibi una ráfaga de invitaciones.

Así, csta actualidad mexicana de la mucrte revcla su horizonte social, su condición histórica resuclta por la crítica que responde y demanda. Ya no es la mucrte gratuita y folklórica que ilustra el poco valor de la vida. La pocsía le da sentido en una vida afirmada por la experiencia comunitaria. Lecr literatura mexicana cs reafirmarse en csa expcriencia. 
